\title{
On the English Translation of Chinese Advertisements from the Perspective of Elegantization and Popularisation
}

Wang Feng Zhu Yunhui \& Ma Yan

Yangtze University

\section{ABSTRACT}

Based on an analysis of the characteristics and functions, we aim to study the English translation of Chinese advertisements from a new perspective of elegantization and popularisation. According to the research, three main factors influence the translation strategy of elegantization and popularisation: functional orientation, price positioning, and consumers' social class. Elegantization is to make the language more beautiful, and the sentence structure more complex. Sometimes, poetic forms and poetic expressions are used. Popularisation is to use simple words and simple sentence structures to help the target audience better understand the characteristics of goods. In translation practice, translators are supposed to not only thoroughly understand the characteristics of Chinese advertisements, master the intention of advertisements, but also understand the characteristics of the target audience to appropriately translate the original Chinese advertisements, to enhance product recognition, and to arouse customers' interests in buying the products.

Keywords: chinese advertisements; english translation; elegantization; popularisation.

Classification: FOR code: 200302

Language: English

London

Journals Press
LJP Copyright ID: 573321

Print ISSN: 2515-5784

Online ISSN: 2515-5792

London Journal of Research in Humanities and Social Sciences 



\title{
On the English Translation of Chinese Advertisements from the Perspective of Elegantization and Popularisation
}

\author{
Wang Feng ${ }^{\alpha}$ Zhu Yunhui ${ }^{\sigma} \&$ Ma Yan ${ }^{\rho}$
}

\begin{abstract}
Based $^{1}$ on an analysis of the characteristics and functions, we aim to study the English translation of Chinese advertisements from a new perspective of elegantization and popularisation. According to the research, three main factors influence the translation strategy of elegantization and popularisation: functional orientation, price positioning, and consumers' social class. Elegantization is to make the language more beautiful, and the sentence structure more complex. Sometimes, poetic forms and poetic expressions are used. Popularisation is to use simple words and simple sentence structures to help the target audience better understand the characteristics of goods. In translation practice, translators are supposed to not only thoroughly understand the characteristics of Chinese advertisements, master the intention of advertisements, but also understand the characteristics of the target audience to appropriately translate the original Chinese advertisements, to enhance product recognition, and to arouse customers' interests in buying the products.
\end{abstract}

Keywords: Chinese advertisements; English translation; elegantization; popularisation.

Author $\alpha \sigma \rho$ : Yangtze University School of Foreign Studies, Yangtze University, No. 1, Nanhuan Road, Jingzhou City 434023, Hubei Province, China.

\footnotetext{
1 This work was supported by the Ministry of Education Humanities and Social Sciences 2015 Youth Fund under Grant [15YJC740078].
}

\section{INTRODUCTION}

Advertisements language is not just a commercially motivated language; it is a highly skilled art. In his book English in Advertisements, Geoffrey Leech, a famous British linguist, stressed that the advertisements language must be vivid, attractive, readable, memorable, and with a strong sale force (Leech, 1966). The English translation of Chinese commercial advertisements will not only allow China's commodities to go to the world but also contribute to the construction of its economic power. It will also promote the world's understanding of China and its culture.

With the rapid development of global economy, the import and export of products between countries have become a common phenomenon. More and more manufacturers are aware that the English translation of Chinese advertisements is crucial for the promotion of products. Since the reform and opening up, China has seized the opportunities brought by economic globalisation and quickly became the world's important commodity manufacturing centre. Goods made in China are sold to Europe, America, and around the world. Countries in the world make huge profits in economic globalisation through commercial advertisements. The role of advertisements is mainly to promote consumption. In addition to maximising the economic interests of the commodity, the English translation of Chinese advertisements can also enhance the understanding and communication between different cultures. Chinese commercial advertisements not only help China's goods to go to the world and contribute to the building of a strong economic power, but also make the world 
better understand China and its culture. However, how to vividly convey various information and cultural spirit of the original Chinese advertisements still needs more research.

In recent decades, more and more attention has been paid to the research of advertisements translation at home and abroad. It is increasingly valued by scholars, but existing researches are mainly at a micro-level, which is mostly a technical and experiential summary of translation practice. This article will analyse advertisements translation from the perspective of elegantization and popularisation, thus bringing a new perspective. Actually, elegantization and popularisation are particularly worthy of attention in the process of language development. Elegantization, in which profound words and complex sentence structures are used, is quite common in advertisements translation, while popularisation, usually manifested in the secularisation and colloquialization of language is also quite common. Some advertisements translated with either elegantization or popularisation can be accepted and recognised by consumers of different cultures and different literary levels, because they are close to the general public's life, and may even become a social pop language of a certain period, for it is easy to read and memorise.

Advertisements industry has been restored and reconstructed in mainland China for more than 30 years, during which it made remarkable achievements. In the meantime, theoretical research on the practice of advertisements was reported frequently. Journals such as "Chinese Translators Journal" and "Shanghai Journal of Translators" provided convenient platforms for academic exchange among advertisements translators. The research related to advertisements translation has gone from scratch, from less to more, from translation skills to translation theories, from translation theories to translation ideas, from micro to macro. San \& L (2003) explored the transfer of cultural images in Chinese advertisement and proposed four basic strategies, namely, preservation, substitution, addition, and cancellation. Wu \& Qiu (2005) pointed out that the concept of intertextuality provided both a new perspective and a new methodology for the study of theories and practices of advertising translation. Li \& Ma (2005) provided a general review of relevant articles and books on Chinese advertisement, pointing out its principles, current problems, and future orientation. Wei (2008) proposed that advertising translation requires a dynamic balance between aesthetic pursuit and practical utility, producing an artistic effect of appealing to both refined and popular tastes. Xiao (2012) discussed the possible unity of artistic and scientific character of advertising translation by analysing relevant theories and typical examples. Chen (2012) believed that the advertising translator should take into consideration the various kinds of context in translation, use the translation strategy of "multi-dimensional adaptation" and adapt to the consumers' needs from different dimensions, thus achieving the intended advertising effect and fulfilling the advertiser's communicative intention. Lv (2016) stated that translators should have cross-cultural awareness of cross-cultural differences to convey the cultural connotations in advertisements. Lai (2017) believed that in translating advertisements, translators should appropriately use the translation strategies of domestication and foreignization to reach functional equivalence. It is evident that more and more foreign language learners, foreign language educators and foreign language researchers are willing to participate in the research of advertisements translation. From the perspective and content of advertisements research in the works, they mainly focus on the following four aspects: advertisements translation strategies and skills, language features in advertisements translation, cultural factors in advertisements translation, and textual features in advertisements and their translations.

\section{CHARACTERISTICS OF CHINESE ADVERTISEMENTS}

Generally speaking, Chinese advertisements are very exquisite, with a unified form and 
readability. The most apparent feature in advertisements is the use of four-character structure, especially when introducing the product performance and efficacy, for example: 美轮美角 “beautiful”，传统工艺“traditional craft”，现代科技 “modern science and technology”, 质量上乘 "high quality”，设计新颖“novel design”，历史悠久“long history", etc.

Secondly, polysemy is popular in Chinese advertisements. In other words, Chinese ads often use words of more than just one meaning and take advantage of people's stereotypical thinking mode based on the general meaning with which people are familiar. Many of the polysemous words in Chinese are used for advertisements. The particular meaning, literal meaning, and connotative meaning make the advertisement full of wit and humour. From the psychological point of view, the novelty will catch people's attention, and then stimulate interest, and enhance memory (Pan, 2008). When people first look at an advertisement, they usually catch the general meaning and the surface meaning of the word. When it comes to further deliberation and reflection, they will surprisingly find another meaning of the word. In this way, advertisements successfully arouse the reader's curiosity, impress them, and enhance the appeal of advertisements. For example, in the ads of Ali Mountain watermelon seeds: 阿里山瓜子 一嗑就开心 "Ali Mountain watermelon seeds, a nibble of happiness." The Chinese characters 开心 meaning "happiness", indicates that the watermelon seeds can make people happy. Additionally, 开心 also means that the seeds are easily opened for eating.

Thirdly, distortion of meaning exists in Chinese advertisements. Such advertisements deliberately distort the meaning of the word by associating the literal meaning of some words with the attributes of the product. This method can not only clearly express the main characteristics of the product, but produce new meanings beyond the literal meaning. From the psychological point of view, it gives customers a feeling of novelty, thus making it impressive to them. For example, in a gold jewellery advertisement 戴(带)来属于你的魅力 "wear (bring) it to have all your charms", the word "戴" means "be respected", but it was deliberately distorted to mean "bring" 带. Thus, the word 戴 can impress people and make people feel respected when they buy gold jewellery.

\section{CHARACTERISTICS OF ENGLISH ADVERTISEMENTS}

To know better about the characteristics of Chinese advertisements, we need to bear in mind their English counterpart. From the stylistic point of view, English advertisements are mostly in oral language. 1) Simple words are preferred. For example, "The taste is great!" Tastes great! (Nestle coffee); "I love it!" (McDonald's). The reason why these two international brands are well-known to young and old in China is that they use simple words to catch consumers' attention and arouse their interests quickly. The possessive form is more frequently used than "of" as in "Lotte, the VIP's choice" (Lotte Hotel). 2) The sentence structure is relatively simple, and the sentence length is generally very short. It is shown in "Every man has his price" (Scotch whiskey). Besides, the grammar and verb phrases are also very simple, and the passive voice and past tense are seldom used. The present tense is the better choice because it makes the characteristics of goods seem as permanent as the general natural law, as shown in "True values never change" (Diamonds).

Secondly, in English advertisements, rhetoric is used extensively, which includes metaphor, pun, anthropomorphic, repetition and so on. For example, "Light as a breeze, soft as a cloud" (metaphor, clothing ad.); "Have a good time" (pun, Certina-DA watches). (Gu, 2004) Fourthly, words in English advertisements are usually more objective and specific, emphasising the precise and general characteristics of the advertised. Mostly, an advertisement begins with a picture carrying specific meanings and finally presents the finishing touch of a slogan, which focuses on the direct publicity effect of enterprises and products (Shen, 2004). 
Thirdly, English advertisements tend to use innovative vocabulary; the purpose is to make the advertisements original and give people a new feeling. There are two main forms of vocabulary innovation. 1) Coinage. Many advertisements deliberately reduce the prefix or suffix that people are familiar with or add a prefix or suffix to create new words. The new word not only retains the original meaning but conveys something different in a completely new way. For example: "The Orangemostest Drink in the World, which equals to the world's highest quality orange juice." Here the new word "Orangemostest" consists of "Orange + most + -est, while both "most" and "-est" are used to form the superlative adjectives. Its purpose is to exaggerate the highest quality and highest purity of this orange juice and makes it impressive to customers. Another example: "Give a Timex to all, to all a good time." The word Timex consists of time and "-x", meaning "excellent", whose purpose is to highlight the accurate timing of the watch. 2) Wrong Spelling. The advertisement creator deliberately misspells the English word to achieve the purpose of being novel, peculiar and eye-catching. For example, a British milk advertisement "Drink a Pinta Milk a Day" advises people to drink a bottle of milk every day. The correct expression should be: "Drink a pint of milk a day." It cleverly combines different advertisement texts through liaison. Because of this popular advertisement, "pinta" has become synonymous with milk. If the milk price goes up, the British do not say "Milk has gone up", but reports that "Pinta has gone up". At this time, the advertisements effect, in turn, will affect the use of advertisement words and language features. 3) Evaluative adjectives. English advertisements often apply evaluative adjectives to attract consumers' attention by giving emotionally strong evaluation and description, including "more beautiful", "more delicious", "more wonderful", "truer", "newer", "super”, "real”, "bright”, “easy", "rich", etc. Let us look at some specific advertisements. "Delicate, mellow and enjoyable. (Mild brand cigarettes)", "New colour, New recipe, New Dial (Dial soap)"; "Let us make things better. Let us do better (Philips)", "In short, the firmer your character, the brighter your future. (company recruitment advertisements). With evaluative adjectives, the quality, good performance and other characteristics of the product are vividly shown in front of consumers.

\section{ELEGANTIZATION AND POPULARISATION IN TRANSLATING CHINESE ADVERTISEMENTS}

Elegantization is concerned with the refined, and exquisite culture, while popularisation is related to the more extensive, simple but fresh, lively and more interesting fashion culture. As for the two cultures, the elegant culture is standardised and stable and has a higher educational function, while the popular culture is rich and vivid, and plays a more prominent role in the mass. (Chen, 1999) As for elegantization, it is shown in the advertisements of some tobacco companies:

1) 青山绿水 碧玉成溪Blue mountains and green rivers are like jaspers in streams. (Yunnan Yuxi (Jasper Stream) Cigarettes)

2）一品黄山 天高云淡 A taste of Huangshan Mountain makes the sky higher and cleaner. (Huangshan Mountain Cigarettes)

According to Chinese laws and regulations, the tobacco industry should either highlight a peaceful spiritual world or create a clean and bright environment rather than directly advertise the function of the product. As a result, some tobacco advertisements form a style featuring pure and elegant language, which leave a deep impression on the consumers.

Popularisation in advertisements is mainly reflected in the secularisation and colloquialization of language. It can be accepted and recognised by consumers of different literacy levels, for it is close to the general public's life, and may even become a social pop language of a certain period, for it is easy to read and memorise. E.g.:

1) 怕上火, 就喝王老吉Afraid of getting angry, just drink Wanglaoji! (Wanglaoji Chinese herbal tea) 
2) 孔府家酒 叫人想家Confucian Family wine makes people miss their family.

(Confucian Family Wine)

As shown above, simple and less modified advertisements language is not only natural to read, remember, and spread but is highly spoken of by many advertisers. The above cases leave a deep impression on customers and play an essential role in enhancing the visibility of products and enterprises.

\section{MAIN FACTORS INFLUENCING THE TRANSLATION OF CHINESE ADVERTISEMENTS}

As the great translation theorist Eugene A. Nida stated, "Translating means communicating, ... What is important is the extent to which receptors correctly understand and appreciate the translated text” (Nida, 1997: 116) Every translation is intended to achieve a particular communicative purpose in the target audience, and if we analyze who the target audience will be and what they may need and expect, we might be better able to deliver a product that suits their needs and expectations. (Nord, 2001: 4) The new notion of elegantization and popularisation provides translators with a new perspective. However, it still needs research on under what circumstances, elegantization or popularisation should be preferred. The following are some factors that we should consider in the translation of advertisements if we want to convey various information and cultural spirit of original advertisements vividly.

\subsection{Functional positioning}

Functional positioning means the advertisements intentionally highlight the particular function of the product so that the product has better performance and quality than other similar products. In this way, it can obtain an outstanding and vivid effect. In real life, consumers generally select the product according to their actual needs, so they are very concerned about the function and practical value of the product. The enterprise should accurately position the outstanding function of the product, such as its security function, comfort function, aesthetic function, high-efficiency function and so on, to meet the specific needs of the consumers. Generally speaking, commodity that meets the needs of consumers can be divided into tangible and intangible: the former refers to the practical value of the commodity entity, it can give the consumers actual material enjoyment; the latter refers to the added value of a concept or service, it can give consumers spiritual pleasure and satisfaction. In the advertisements campaign, the functional positioning of a product will, in no small extent, affect the style and taste of advertisements language. Under normal circumstances, if a product is for daily necessities, its value of the material function is dominant. For example,

1）乐百氏27层净化Robust: after 27 layers of purification (Robust Pure Water)

2) 好空调, 格力造Good air conditionings are made by Gree; (Gree Air-Conditioning)

The above slogans all emphasise the high quality of the product by applying plain and simple words. In the 1990s, with the gradual improvement of living standards, people began to pay attention to the quality of drinking water. Robust's ad campaign shaped a healthy, clean and pure image in the customers' mind, and thus quickly won the trust of consumers. Gree air-conditioning advertisements also highlight the reliable quality of the product as well as its practical features and beautiful shape. It not only promotes the product itself but also improves the visibility of the enterprise, which received a win-win effect. Under such circumstance, the translation strategy of popularisation should be used.

\subsection{Price positioning}

The positioning of prices not only affects the relationship and behaviour of producers, brokers and consumers but also affects the performance and communication of advertisements language to a large extent. In general, if the commodity is of 
high price, the advertiser tends to use elegant language to create a certain atmosphere to highlight the noble status or decent taste of the target group; and for commodities that meet the most basic needs of the ordinary people, the advertiser tends to use everyday and simple language to convey the product information. When customers purchase the commodity, they may link the price with their economic status, cultural accomplishment, life pursuit, etc. Therefore, to meet the needs of different consumer groups, translators should decide whether elegantization or popularisation is better in reproducing the advertisements according to the price positioning of the product.

\section{E.g.:}

有兄弟，才有阵营Where there are brothers, there are camps (Red Star Erguotou Wine), 红星二锅头, 年轻就要红Red Star Erguotou, being young is being red and hot;

Red Star Erguotou is the first state-owned brewery established by the People's Republic of China and has a history of about 70 years. Based on the principle of enabling people to drink pure Erguotou, the company has heartily provided customers with the best Erguotou at the lowest price. Thus it is favoured by consumers all the time. Now, Red Star Erguotou becomes synonymous with a "good public liquor" and is leading a unique style in advertisements campaign. In translating such an advertisement, the translation strategy of popularisation should be used.

Different from Red Star Erguotou, Shuijingfang is "the Number One Chinese Liquor Workshop" and "the Oldest Liquor Workshop". It carries a broad historical and cultural heritage. Consumers do not only pursue its use value but are more for the recognition of identity and spiritual enjoyment in such high-end liquor brands.

世界上只有两种方向：指引与被指引。

There are only two directions in the world: to show and to be shown.

世界上只有两种角色：追逐与被追逐。
There are only two roles in the world: to follow and to be followed.

\section{世界上只有两种历史：歌颂与被歌颂}

There are only two histories in the world: to eulogise and to be eulogised.

With such majestic slogan, the advertisement shows a unique brand personality of Shuijingfang and its rich cultural connotations to consumers, thus making it the most expensive Chinese liquor among high-end enthusiasts. It is evident that the translation strategy of elegantization should be preferred in translating such advertisements.

\subsection{Consumers' social class}

The customers, the receivers and decoders of advertisements are the destination of advertisements communication. The responses of customers directly determine the success or failure of advertisements. Customers belong to different social groups. The so-called social class means that all members of society are divided into different social groups which are distinct and relatively stable according to their professions, economic incomes, and educational levels. The values, aesthetic consciousness and lifestyles of the same social class have many similarities, while those of different social class are very different. The strategies in advertisement translation should pay close attention to the social class of target groups. Therefore, translators should take into consideration the social class of customers and decide the language style of advertisements and translation strategies according to the demands and tastes of different social classes. Generally speaking, customers of higher social class pay less attention to the price of the product. Instead, they mainly pursue the taste and cultural connotation of the commodity to show their noble status and decent taste.

Consumers with a general economic condition are usually more cautious about their money, and they pay more attention to the consumption of daily necessities. What they buy is to meet their basic needs. Besides, they mostly purchase 
low-end commodities or production materials. Farmers, for example, are more likely to buy practical and cheap commodities. Therefore, consumers of this kind are more accustomed to accepting word-of-mouth advertisements. Colloquial and popular advertisements language is more in line with their aesthetic needs.

For example, to translate the slogan of a low-end Chinese skincare product Dabao, there are at least two versions for the original Chinese slogan “要想 皮肤好, 早晚用大宝”。

1) Applying "Dabao" morning and night / makes your skincare a real delight.

2) Gook skin needs "Dabao" every day.

In the first version, elegantization is used because the poetic form of iambic tetrameter makes the slogan seem elegant; however, it might not be suitable because most of its target customers are not used to such sophisticated expression. However, in the second version, popularisation is used because simple and common words are used with a simple sentence structure. It is easily understood by ordinary customers and might appeal to them more easily.

\section{CONCLUSION}

Due to the impact of Chinese traditional aesthetic consciousness for thousands of years, many people think that "elegant" language in advertisements is bound to be good, positive and upward, and is worth being appreciated, while "popular" language in advertisements is at a lower level. However, the translation of advertisements is a kind of art, and different people have different opinions on whether the language of advertisements should be elegant or popular. There is no clear division about them. In order to highlight the characteristics of goods, advertisements language can be either elegant or popular. Elegantization is to make the language more beautiful, while popularisation is to make the audience better understand the characteristics of goods. Otherwise, even if the language is elegant, they have no vitality since ordinary consumers can not appreciate it. In short, elegantization and popularisation complement with each other in the development of advertisements. The translation strategy of elegantization or popularisation is influenced by functional positioning, price positioning, and consumers' social class. Elegantization is to make the language more beautiful; the sentence structure more complex. Sometimes, poetic forms and poetic expressions are used. Popularisation is to use simple words and simple sentence structure, to help target audience better understand the characteristics of goods. Translators are supposed to not only thoroughly understand the characteristics of Chinese advertisements, master the intention of advertisements, but also understand the characteristics of the target audience to convey the information and intention accurately in the original advertisements, to enhance their products recognition, and to arouse the customers' interests in buying the products. In theory, elegantization and popularisation form a continuum of translation strategies, similar to domestication and foreignization. This perspective is new and useful in studying the English translation of Chinese advertisement and worth more research in other fields.

\section{REFERENCE}

1. Chen, Dongcheng. On the Contextual Adaptation in Advertising Translation [J]. Journal of Shenzhen University (Humanities and Social Sciences Edition), 2012 (2).

2. Chen, Yuanlong \& Liu Jie'er. On the Popularization of Literature [J], Xi'an University of Electronic Science and Technology (Social Science Edition), 1999 (3).

3. Cui, Ying. The transference of poetic quality in the translation of English-Chinese advertisements, Perspectives, 2017, 25: (1).

4. $\mathrm{Gu}$, Yunfeng. Language and Culture Differences and Their Impact on Advertisement Translation [J], Journal of Ningbo University(Liberal Arts Edition), 2004 (2). 
5. Lai, Weiling. Translation of Cosmetic Advertisements from a Cultural Perspective [J]. Journal of Guangxi Normal University for Nationalities, 2017 (3).

6. Leech, G. N. English in Advertisements: A Linguistic Study of Advertisements in Great Britain [M]. London: Longman, 1966.

7. Li, Zhen, Ma Caimei. A Study of Domestic Advertisement Translation Studies [J]. Chinese Science \& Technology Translators Journal, 2005 (1).

8. Lv, Zheng. A Study of Tourism Advertising Translation from a Cross-cultural Perspective [J]. Shanghai Journal of Translators, 2016 (1).

9. Nida, E. A. Language, Culture, and Translating $[\mathrm{M}]$. Shanghai: Shanghai Foreign Language Education Press, 2001.

10. Nord, C. Translating as a Purposeful Activity: Functional Approaches Applied [M]. Shanghai: Shanghai Foreign Language Education Press, 2001.

11. Pan, Tsinghua. Comparison and Translation of Advertising Language between English and Chinese [J], Journal of Jiangxi University of Finance and Economics, 2008 (5).

12. San, You, Li Jing. Cultural Image Conversion in Advertising Translation [J]. Chinese Science \& Technology Translators Journal, 2003 (3).

13. Shen, Jicheng. Functional Equivalence \& C-E Ad. Translating [D], A Thesis submitted to Guangxi Normal University, 2000.

14. Wei, Jin. A Dynamic Balance Between Refinement and Popularity in Advertising Translation [J]. Foreign Language Research, 2008 (5).

15. Wu, Zhongming, Qiu Jin. The Application of Intertextuality to Advertising Translation [J]. Shanghai Journal of Translators for Science and Technology, 2004 (2).

16. Xiao, Xinying. The Unity of Science and Art in Advertising Translation [J]. Chinese Science \& Technology Translators Journal, 2012 (2). 